\title{
Correction to: QTc interval analysis-an ever-evolving endeavor
}

\section{Peter L. Bonate ${ }^{1}$}

Published online: 22 April 2021

(C) Springer Science+Business Media, LLC, part of Springer Nature 2021

\section{Correction to: Journal of Pharmacokinetics and Pharmacodynamics} https://doi.org/10.1007/s10928-021-09754-z

The original version of this article unfortunately contained a mistake. The author Henrich et al. was misspelled as Heinrich et al.

Further, references 23 and 24 are in the incorrect order. The correct order is:

[23] Henrich A, Juif P-E, Dingemanse J, Krause A (2021) PK/PD modeling of a clazosentan thorough QT study with hysteresis in concentration-QT and RR-QT. J Pharmacokinet Pharmacodynam. https://doi.org/10.1007/s10928020-09728-7

[24] Orihashi Y, Ohwada S, Kumagai Y (2021) Concentration-QTc analysis for single arm studies. J Pharmacokinet Pharmacodynam. https://doi.org/10.1007/s10928021-09737-0

Publisher's Note Springer Nature remains neutral with regard to jurisdictional claims in published maps and institutional affiliations.

The original article can be found online at https:// doi.org/10.1007/s10928-021-09754-z.

Peter L. Bonate

Peter.Bonate@astellas.com

11 Astellas Way, N3.154, Northbrook, IL 60062, USA 